Çukurova Üniversitesi Mühendislik Mimarlık Fakültesi Dergisi, 31(ÖS 2), ss. ÖS 135-ÖS 142, Ekim 2016

Cukurova University Journal of the Faculty of Engineering and Architecture, 31(SI 2), pp. SI 135-SI 142, October 2016

\title{
Fotovoltaik Güneş Panellerinin Sıvıya Daldırma Yöntemi ile Soğutulmasında Kanal Geometrisi ve Panel Konumunun Etkisi
}

\author{
Burak KURŞUN ${ }^{1}$, Korhan ÖKTEN ${ }^{* 1}$, Gonca DEDE ${ }^{2}$ \\ ${ }^{1}$ Amasya Üniversitesi, Teknoloji Fakültesi, Makine Mühendisliği, Amasya \\ ${ }^{2}$ Amasya Üniversitesi, Teknoloji Fakültesi, Otomotiv Mühendisliği, Amasya
}

Geliș tarihi: 18.08.2016 Kabul tarihi: 10.10 .2016

$\ddot{\mathbf{O} z}$

Güneş enerjisinden elektrik enerjisi üreten sistemlerde fotovoltaik hücrelerin soğutulması sistem verimini artırmaktadır. Bu hücrelerin soğutulması için birçok yöntem ve parametre mevcuttur. Bu çalışmada alt yüzeyinde kanatçıklar bulunan fotovoltaik güneş panelinin dielektrik sıvıya daldırma yöntemi ile soğutulmasında soğutma kanalı geometrisi ve panel konumunun fotovoltaik hücre sicaklıklarına etkisi sayısal olarak incelenmiştir. Sayısal analizler kanal çıkış genişliği, panelin eksenel ve radyal yöndeki konumu parametreleri için gerçekleştirilmiştir. Ayrıca, parametre değerlerinin değişimi ile oluşan ek basınç kayıpları hesaplanarak soğutma için gerekli enerji gereksinimi ortaya konulmuştur. Analizler sonucunda kanal çıkışının daraltılması ve panelin eksenel konumunun kanal çıkışına yakın olması durumunda fotovoltaik hücreler için daha etkin soğutma sağlandığı gözlemlenmiştir. Sayısal çalışma sırasında elde edilen bulgular sıcaklık, basınç değişimi, hız ve sıcaklık kontörlerini içeren grafikler halinde ayrıntılı olarak sunulmuştur.

Anahtar Kelimeler: Fotovoltaik hücre, Güneş paneli, Sıvıya daldırma

\section{Effect of Channel Geometry and Panel Position at Cooling of Photovoltaic Solar Panels with Liquid Immersion Method}

\begin{abstract}
Today, energy consumption have increased significantly because of developed technology. Therefore, using of fossil fuels have increased step by step. All of these have caused increasing of renewable energy sources and sustainable energy researches. In this study, the effect of cooling channel geometry and panel position on the temperature of photovoltaic cells are investigated at cooling of the photovoltaic solar panel that has fins on its bottom surface, with liquid immersion cooling method, numerically. Numerical analyses are carried out for parameters of channel outlet width, axial and radial position of the panel. Also, additional pressure losses that occurred with variation of parameter values are calculated and energy requirement is introduced for cooling. In consequence of analyses, it is observed that more effective cooling is provided in the case of narrowing of the channel outlet and panel position is close to channel outlet. Findings obtained during the numerical study are presented as graphics that include temperature, variation of pressure, and velocity contours in detail.
\end{abstract}

Keywords: Photovoltaic cell; Solar panel; Liquid immersion

"Sorumlu yazar (Corresponding author): Korhan ÖKTEN, korhan.okten@amasya.edu.tr 


\section{GíRiș}

Son yıllarda, artan enerji ihtiyacını karşılamak amacı ile yenilenebilir enerji kaynaklarına olan ilgi artmıştır. $\mathrm{Bu}$ enerji kaynaklarının en önemlilerinden biri de güneş enerjisidir. Güneş enerjisinden elektrik üreten fotovoltaik sistemler giderek artmakta ve bu sistemlerin iyileştirilmesine ilişkin çalışmalar önem arz etmektedir.

Fotovoltaik sistem tasarımında en önemli parametreler; düşük ve düzgün dağılımlı hücre sıcaklığı, sistem güvenilirliği ve kapasite yeterliliğidir. Ancak, fotovoltaik hücrelerin soğutulması bu tür sistemlerde en büyük sorun olarak görülmektedir. $\mathrm{Bu}$ durum fotovoltaik hücrelerin $\% 25$ verimle çalışmasından dolayı kayıp enerjinin bir kısmının 1s1 enerjisine dönüşmesiyle meydana gelmektedir. $\mathrm{Bu}$ hücrelerdeki aşırı sıcaklık artışı kısa vadede verim düşüşüne sebep olurken uzun vadede geri dönüşü olmayan arılara neden olabilmektedir [1]

Fotovoltaik sistemlerin soğutulması aktif ve pasif olmak üzere iki şekilde yapılabilir. Pasif soğutma genellikle isınan yüzeye kanatçıklar yerleştirilmesiyle gerçekleşmektedir. Aktif soğutma ise fotovoltaik hücrelerin 1sınan yüzeylerinin akışkan vasıtasıyla soğutulmasına dayanmaktadır [2]. Yüksek yoğunluklu güneş ışınlarının etki ettiği sistemlerde aktif soğutmanın daha etkin olduğu görülmüştür [3].

Fotovoltaik hücrelerinin sicaklık değerinin düşürülmesi ve yüzeye üniform dağılması sistem verimini artırmaktadır [4]. Literatürde bu saptamadan hareket ile yapılan birçok çalışma bulunmaktadır. Flourscheutz, pasif soğutma sistemlerini düz ve kanatlı düzlemler için karşılaştırmıştır. Kanatlı yüzeylerin düz yüzeylere göre daha iyi performans gösterdiği belirlenmiştir. Ancak kanatlı yüzey imalatı maliyetli olduğundan iyi bir seçenek olarak görülmemiştir. $\mathrm{Bu}$ çalışmanın sonucunda düşük yoğunluklu güneş 1şınları için düz yüzeyler yeterliyken yüksek yoğunluklu güneş 1şınları için kanatlı yüzeyler kullanmanın daha uygun olduğu görülmüştür [5]. Cui ve arkadaşları, 400 suns değerinde herhangi bir soğutma olmadan fotovoltaik hücre sıcaklığının $1200^{\circ} \mathrm{C}$ olacağını ön görmüştür. Ancak soğutucu bir panel kullanıldığında bu değerin önemli ölçüde azalacağı ve hücre sıcaklığının $37^{\circ} \mathrm{C}$ 'ye düşeceği belirlemişlerdir [6]. Natarajan ve arkadaşları, fotovoltaik güneş hücrelerinin soğutulması ile ilgili pasif soğutmalı ve soğutma sistemi olmayan iki modeli kıyaslamışlardır. Bu çalışmanın sonucunda $5 \mathrm{~mm}$ boyunda ve $1 \mathrm{~mm}$ kalınlığında kanatlı modelin en verimli model olduğu görülmüştür [7]. Coventry [8], fotovoltaik hücreleri soğutmak için aktif soğutma yöntemi ve soğutucu akışkan olarak su kullanmıştır. Bunun yanında korozyona ve donmaya karşı, suya katkı maddeleri eklenmiştir. $\mathrm{Bu}$ karışım bir pompa yardımı ile basınçlandırılarak hücrelerin soğutulması ve ısının geri kazanılması için kullanmıştır. Ek olarak soğutma yüzeyine kanatçıklar yerleştirerek 1s1 transferi yüzey alanını artırmış ve sonuçları incelemiştir. Yang Sun ve arkadaşları doğrudan daldırmalı soğutma için dikdörtgen kanal kullanarak farklı sıvılar için verimlilik analizi yapmıştır. Yapılan çalışmada daldırma sıvısı kalınlığının ve kanal geometrisinin verimliliğe etkisini incelemişlerdir [9].

$\mathrm{Bu}$ çalışmada, fotovoltaik hücrelerin soğutulması sırasında, kanal çıkış boyutlarına, panelin eksenel ve radyal konumunun fotovoltaik hücre sicaklığına olan etkisi incelenmiştir. Bunun yanında geometri ve konum değişimlerinin oluşturacağı basınç kayıpları belirlenmiş ve sonuçlar sıcaklık, basınç değişimi ve hız kontörlerini içeren grafikler halinde ayrıntılı olarak sunulmuştur.

\section{FİZIKSEL MODEL}

Şekil 1'de çalışmada ele alınan silindirik soğutucu kanal ve alt yüzeyinde kanatçıklar bulunan fotovoltaik güneş paneli geometrisi görülmektedir. Kanal, fotovoltaik hücre ve panel ölçüleri deneysel sonuçlarla karşılaştırılması amacı ile Xiang ve arkadaşları [10] tarafindan yapılan çalışmadaki ölçülerle aynı alınmış ve soğutucu akışkan olarak deiyonize (saf) su kullanılmıştır. Şekil 2'de ise 1s1 transferini artırılması amacı ile değiştirilmiş kanal geometrisi verilmiştir. Analizlerde kanal çıkış1 farklı oranlarda daraltılmış ve panel eksenel ve radyal yönde farklı konumlara yerleştirilmiştir. 
Güneş paneli 88 adet silisyum fotovoltaik hücreden ve bakır kanatçıklı panelden oluşmaktadır. Soğutucu kanal ise cam malzemedir. Xiang ve arkadaşları [10] tarafindan gerçekleștirilen çalıșmada enine yönde sıcaklık değişiminin ihmal edilebilir seviyede olması nedeni ile bu çalışmada geometri iki boyutlu olarak ele alınmıştır (Şekil 2).

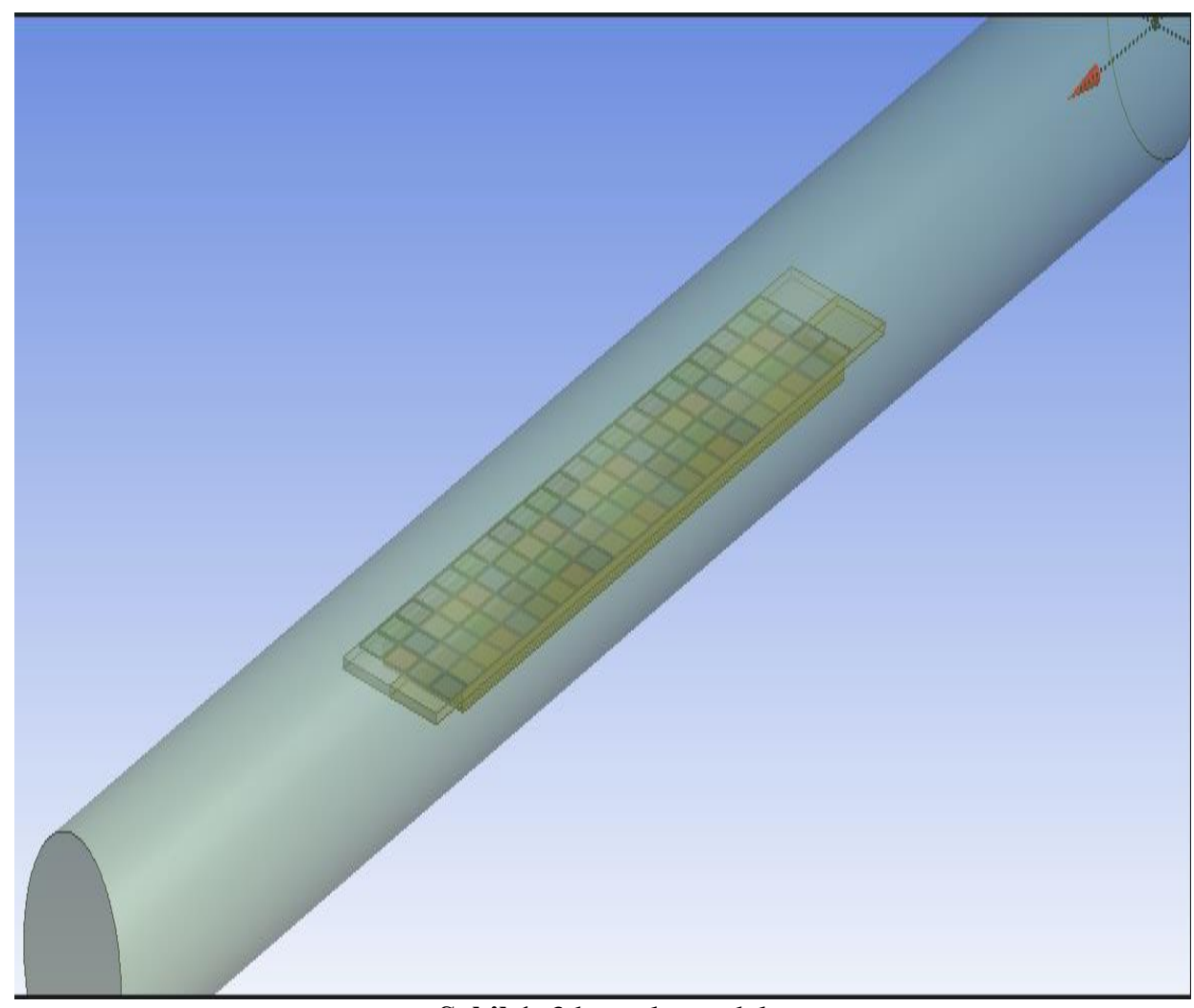

Şekil 1. 3 boyutlu model

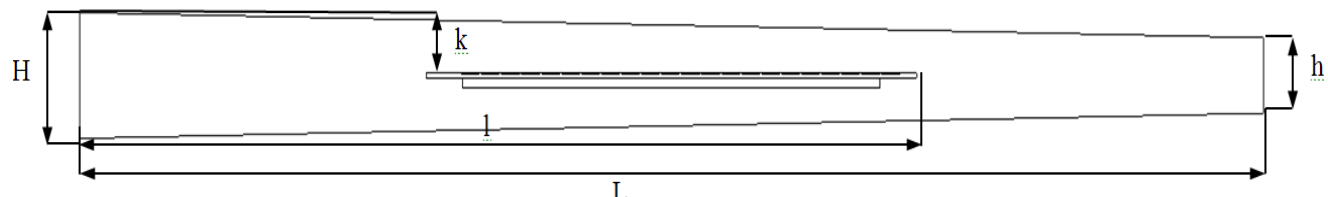

Şekil 2. İki boyutlu model

\section{SAYISAL MODEL}

Çalışmada akışkanın sıkıştırılamaz, Newtonian ve taşınım özelliklerinin sabit olduğu kabul edilerek analizler kararlı ve türbülans akış koşulları için gerçekleştirilmiştir. Eksenel yöndeki sıcaklık dağılımının elde edilmesi için kullanılan temel korunum denklemleri kartezyen tensör formunda eşitlik 1'de verilmiştir. Temel korunum denklemleri, süreklilik (1), momentumun korunumu (2 ve 3) ve enerji denkleminden (4) oluşmaktadır.

Süreklilik denklemi: $\frac{\partial(\overline{\rho \mathrm{u}})}{\partial \mathrm{x}}+\frac{\partial(\overline{\rho \mathrm{y}})}{\partial \mathrm{x}}=0$ 
$\mathrm{x}$ - Momentum: $\left(\frac{\partial(\overline{\rho \mathrm{uu}})}{\partial \mathrm{x}}+\frac{\partial(\overline{\rho \mathrm{vu}})}{\partial \mathrm{y}}\right)=-\frac{\partial \overline{\mathrm{P}}}{\partial \mathrm{x}}+\frac{\partial}{\partial \mathrm{x}}\left(\left(\mu+\mu_{\mathrm{t}}\right) \frac{\partial \overline{\mathrm{u}}}{\partial \mathrm{x}}\right)+\frac{\partial}{\partial \mathrm{y}}\left(\left(\mu+\mu_{\mathrm{t}}\right) \frac{\partial \overline{\mathrm{u}}}{\partial \mathrm{y}}\right)+\frac{\partial}{\partial \mathrm{x}}\left(\mu \frac{\partial \overline{\mathrm{u}}}{\partial \mathrm{x}}\right)+\frac{\partial}{\partial \mathrm{y}}\left(\mu \frac{\partial \overline{\mathrm{v}}}{\partial \mathrm{y}}\right)$

$\mathrm{y}$ - Momentum: $\left(\frac{\partial(\overline{\rho \mathrm{uv}})}{\partial \mathrm{x}}+\frac{\partial(\overline{\rho \mathrm{vv}})}{\partial \mathrm{y}}\right)=\rho \mathrm{g}-\frac{\partial \overline{\mathrm{P}}}{\partial \mathrm{y}}+\frac{\partial}{\partial \mathrm{x}}\left(\left(\mu+\mu_{\mathrm{t}}\right) \frac{\overline{\partial \mathrm{v}}}{\partial \mathrm{x}}\right)+\frac{\partial}{\partial \mathrm{y}}\left(\left(\mu+\mu_{\mathrm{t}}\right) \frac{\overline{\partial \mathrm{v}}}{\partial \mathrm{y}}\right)+\frac{\partial}{\partial \mathrm{x}}\left(\mu \frac{\partial \overline{\mathrm{u}}}{\partial \mathrm{y}}\right)+\frac{\partial}{\partial \mathrm{y}}\left(\mu \frac{\partial \overline{\mathrm{v}}}{\partial \mathrm{y}}\right)$

Enerji: $\frac{\partial}{\partial \mathrm{x}}\left(\overline{\rho \mathrm{uc}}_{\mathrm{p}} \overline{\mathrm{T}}\right)+\frac{\partial}{\partial \mathrm{y}}\left(\overline{\rho \mathrm{v}}_{\mathrm{p}} \overline{\mathrm{T}}\right)=\frac{\partial}{\partial \mathrm{x}}\left(\left(\mathrm{k}_{\mathrm{i}}+\mathrm{k}_{\mathrm{t}}\right) \frac{\partial \overline{\mathrm{T}}}{\partial \mathrm{x}}\right)+\frac{\partial}{\partial \mathrm{y}}\left(\left(\mathrm{k}_{\mathrm{i}}+\mathrm{k}_{\mathrm{t}}\right) \frac{\partial \overline{\mathrm{T}}}{\partial \mathrm{y}}\right)$

Belirtilen denklemlerde $\mathrm{k}_{\mathrm{t}}$, türbülanslı eddy iletkenliği $\mu$, eddy viskozitesi, $\mu_{\mathrm{t}}$ türbülanslı eddy viskozitesi, $\rho$, yoğunluk, $\mathrm{T}$, sicaklık, $\mathrm{u}, \mathrm{x}$ yönündeki hız vektörü, v, y yönündeki hız vektörü, $c_{p}$ özgül 1sı, P, basıncı temsil etmektedir.

Güneş paneli ve silisyum hücreler içerisindeki sıcaklık dağılımlarının hesaplanması için ise kararlı koşullarda iletimle 1sı transferi gerçekleştiği kabul edilerek Denklem 5 ile verilen 1sı iletim denklemi kullanılmıştır.

$\mathrm{k}_{\mathrm{S}} \nabla^{2} \mathrm{~T}=0$
Burada $\mathrm{k}_{\mathrm{s}}$ hesaplama bölgesine bağlı olarak silisyum hücrelerin ya da bakır panelin 1sı iletim katsayısını ifade etmektedir.

\subsection{Standart k- $\varepsilon$ Modeli}

Yukarıdaki diferansiyel denklemlerinin çözülmesi için standart $\mathrm{k}-\varepsilon$ modeli tercih edilmiştir. Türbülans kinetik enerjisi (k) ve kinetik enerjiye bağlı olarak oluşan enerji kayıp oranı $(\varepsilon)$ değerlerinin bulunması için aşağıdaki denklemler kullanılmıştır.

$\mu_{\mathrm{t}}=\mathrm{c} \mu \rho \frac{\mathrm{k}^{2}}{\varepsilon}$ ve $\mathrm{k}_{\mathrm{t}}=\frac{\mu_{\mathrm{t}} \mathrm{C}_{\mathrm{p}}}{\sigma_{\mathrm{t}}}$

$\frac{\partial \overline{\rho \mathrm{uk}}}{\partial \mathrm{x}}+\frac{\partial \overline{\rho \mathrm{vk}}}{\partial \mathrm{y}}=\frac{\partial}{\partial \mathrm{x}}\left(\frac{\mu_{\mathrm{t}}}{\sigma_{\mathrm{k}}} \frac{\partial \mathrm{k}}{\partial \mathrm{x}}\right)+\frac{\partial}{\partial \mathrm{y}}\left(\frac{\mu_{\mathrm{t}}}{\sigma_{\mathrm{k}}} \frac{\partial \mathrm{k}}{\partial \mathrm{y}}\right)+\mu_{\mathrm{t}} \Phi-\rho \varepsilon+\frac{\mathrm{C}_{4} \beta \mu_{\mathrm{t}}}{\sigma_{\mathrm{t}}}\left(\mathrm{g} \frac{\partial \mathrm{T}}{\partial \mathrm{y}}\right)$

$\frac{\partial \overline{\rho \mathrm{u}} \varepsilon}{\partial \mathrm{x}}+\frac{\partial \overline{\rho \mathrm{v}} \varepsilon}{\partial \mathrm{y}}=\frac{\partial}{\partial \mathrm{x}}\left(\frac{\mu_{\mathrm{t}}}{\sigma_{\varepsilon}} \frac{\partial \varepsilon}{\partial \mathrm{x}}\right)+\frac{\partial}{\partial \mathrm{y}}\left(\frac{\mu_{\mathrm{t}}}{\sigma_{\varepsilon}} \frac{\partial \varepsilon}{\partial \mathrm{y}}\right)+\mathrm{C}_{1 \varepsilon} \mu_{\mathrm{t}} \frac{\varepsilon}{\mathrm{k}} \phi-\mathrm{C}_{2} \rho \frac{\varepsilon^{2}}{\mathrm{k}}+\frac{\mathrm{C}_{\mu}\left(1-\mathrm{C}_{3}\right) \beta \rho \mathrm{k}}{\sigma_{\mathrm{t}}}\left(\mathrm{g} \frac{\partial \mathrm{T}}{\partial \mathrm{y}}\right)$

Burada türbülans kinetik enerji üretimi aşağıdaki gibi tanımlanmaktadır.

$\Phi=2\left[\left(\frac{\partial \overline{\mathrm{u}}}{\partial \mathrm{x}}\right)^{2}+\left(\frac{\partial \overline{\mathrm{v}}}{\partial \mathrm{y}}\right)^{2}\right]+\left(\frac{\partial \overline{\mathrm{u}}}{\partial \mathrm{y}}+\frac{\partial \overline{\mathrm{v}}}{\partial \mathrm{x}}\right)$

Diğer türbülans model sabitleri ise $\mathrm{C}_{\mu}=0,09$, $\mathrm{C}_{1}=1,44, \quad \mathrm{C}_{2}=1,92, \quad \mathrm{C}_{3}=1,0, \quad \mathrm{C}_{4}=0,0, \quad \sigma_{\mathrm{k}}=1,0$, $\sigma_{3}=1,30, \sigma_{\mathrm{t}}=0,9$ şeklindedir.

\subsection{Sınır Koșulları}

Diferansiyel denklemlerin çözümünde kullanılan sınır şartlarında kanal giriş bölgesinde hız, sıcaklık ve basınç değişkenleri başlangıç değerinde $\left(\mathrm{u}=\mathrm{u}_{\text {giriş, }}, \mathrm{v}=0, \mathrm{~T}=\mathrm{T}_{\text {giriş, }} \mathrm{P}=\mathrm{P}_{\text {giriş̧ }}\right)$ kanal çıkışında ise basınç haricinde tüm değişkenlerin $\mathrm{x}$ ekseni doğrultusundaki değişimleri sıfır alınmıştır. Katı çeperler üzerinde kaymama koşulu tanımlanmıştır $(\mathrm{u}=0, \mathrm{v}=0)$. Silisyum hücrelerin üst yüzeylerine elektrik üretimi sonrasında oluşan 1sınma miktarını 
modellemek amacı ile sabit 1sı akısı değerleri verilmiştir $\left(\dot{q}=\dot{q}_{\text {snır }}\right)$. Silindirik cam kanalın dış yüzeylerinde ise 1sı akısı değeri sıfır alınarak $(\dot{q}=0)$ yalıtılmış olması sağlanmıştır. Sınır koşulları için verilen değerler Çizelge 1'de görülmektedir.

Çizelge 1. Sınır şartlarının değerleri

\begin{tabular}{|c|c|c|c|}
\hline $\mathbf{u}_{\text {giriş }}(\mathbf{m} / \mathbf{s})$ & $\mathbf{T}_{\text {giriş }}\left({ }^{\circ} \mathbf{C}\right)$ & $\mathbf{P}_{\text {giriș }}(\mathbf{b a r})$ & $\begin{array}{c}\dot{\boldsymbol{q}}_{\text {sinır }} \\
\left(\mathbf{W} / \mathbf{m}^{\mathbf{2}}\right)\end{array}$ \\
\hline 0,32 & 25,1 & 1 & 148000 \\
\hline
\end{tabular}

\section{SAYISAL ÇÖZÜMLEME}

Korunum denklemlerinin ayrıklaştırılması ve çözülmesinde sonlu hacimler yöntemi kullanılmıştır. Öncelikle deneysel sonuçlarla uyum sağlayacak şekilde hücre yapısı oluşturulmuştur. Tüm geometri için $0,5 \mathrm{~mm}$ boyutunda dörtgen hücre yapısı kullanılmış ve katı çeperlerde yı̆̆ılma faktörü 10 alınarak hücre yapısı sıklaştırılmıştır (Şekil 3).

Korunum denklemlerinin ayrıklaştırılmasında birinci dereceden up wind metodu uygulanmış ve hız, basınç ve sıcaklık değerlerinin bulunmasında SIMPLE metodu kullanılmıştır. Sayısal çözümlemeler kalıntı değerlerinin süreklilik, momentum, $\mathrm{k}$ ve $\varepsilon$ denklemleri için $1 \times 10^{-3}$, den, enerji denklemi için ise $1 \times 10^{-6}$, dan az olduğu koşula kadar devam etmiştir.

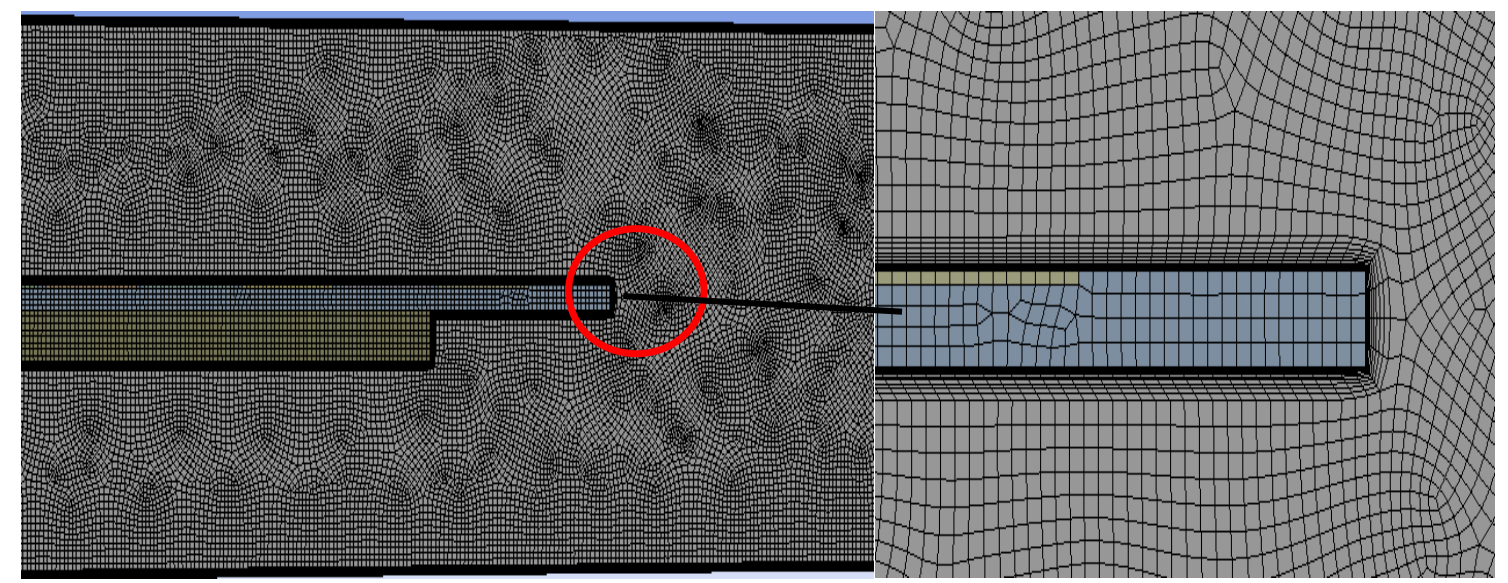

Şekil 3. Hücre dağılımı ve yapısı

\subsection{Sayısal Sonuçların Doğruluğu}

Fotovoltaik panel üzerinde elde edilen sicaklık değerlerinin doğruluğunun ve sayısal çözümün hücre yapısından bağımsızlığının kontrolü amacı ile sayısal sonuçlar farklı hücre boyutları için elde edilmiş ve deneysel sonuçlarla karşılaştırılmıştır. 0,25 ve $0,5 \mathrm{~mm}$ hücre boyutları için sicaklık değerlerinin deneysel sonuçlarla uyum sağladığı ve birbirine çok yakın olduğu görülmektedir (Şekil 4). $\mathrm{Bu}$ nedenle problemin çözümü için hesaplama zamanını kısaltması ve en yüksek hata oranının yaklaşık \%4 olması sebebi ile $0,5 \mathrm{~mm}$ büyüklüğündeki hücre yapısı tercih edilmiştir.

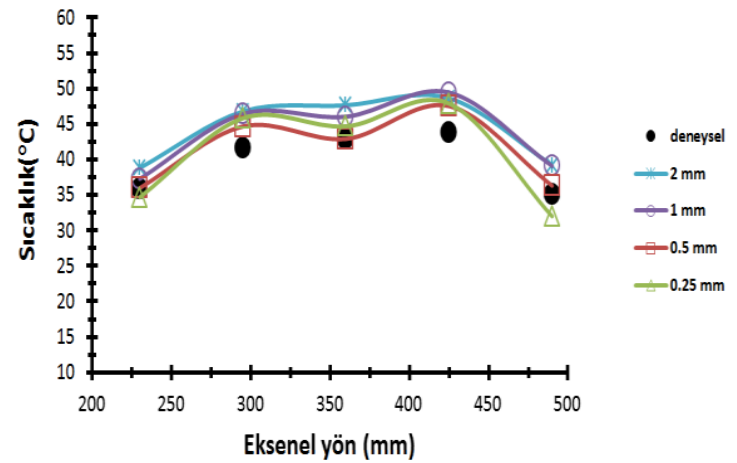

Şekil 4. Sayısal sonuçların deneysel sonuçlarla karşılaştırılması 


\section{BULGULAR VE TARTIŞMA}

Sayısal analizler kanal çıkış genişliği, panelin eksenel ve radyal yöndeki konumu parametrelerinin farklı değerleri için gerçekleştirilmiştir. Parametre değerlerine bağlı olarak oluşan sıcaklık değerleri, basınç kayıpları aşağıda verilen kısımlarda sunulmuştur.

\subsection{Kanal Çıkış Boyutunun Etkisi}

Şekil 5a'da görüldüğü gibi dört farklı h/H oranı için çözümleme yapılmış ve kanal çıkıșının daraltılması sonucunda panel üzerindeki sıcaklıkların düştüğü anlaşılmıştır. Bu durum daralma ile birlikte akışkan hızının kanal çıkışına doğru artmasının taşınım ile 1S1 transferini de artırması sonucu oluşmaktadır (Şekil 6 ve 7).

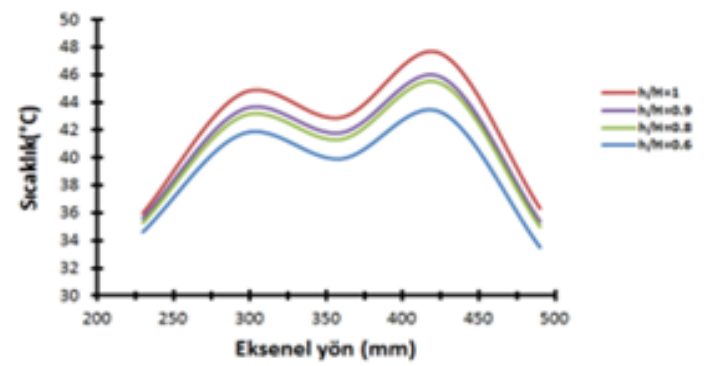

Şekil 5. Kanal çıkış boyutunun etkisi a) hücre sicaklıkları
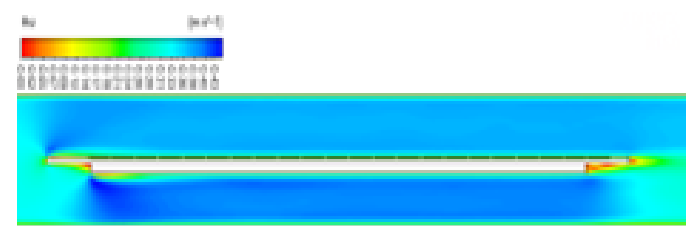

Şekil 6. Kanal çıkıș boyutunun etkisi b) hız kontörleri $(\mathrm{h} / \mathrm{H}=0,6,1 / \mathrm{L}=0,71, \mathrm{k} / \mathrm{H}=0,5$
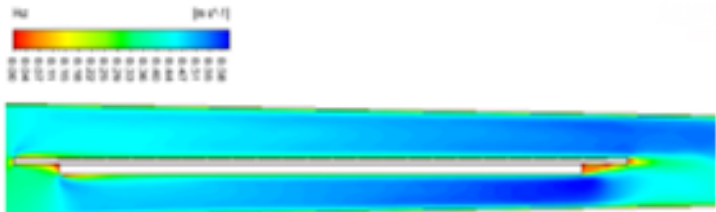

Şekil 7. Kanal çıkış boyutunun etkisi c) hız kontörleri $(\mathrm{h} / \mathrm{H}=1, \mathrm{l} / \mathrm{L}=0,71, \mathrm{k} / \mathrm{H}=0,5)$

\subsection{Panel Konumunun Etkisi}

Güneş panelinin eksenel yöndeki farkli konumlarının sicaklık üzerindeki etkisi incelendiğinde (Şekil 8a) panelin çıkışa yakın bölgeye yerleştirilmesinin hücrelerin sıcaklıklarını düşürdüğ̈̈ görülmektedir. $\mathrm{Bu}$ durum kanal çıkış boyutunun etkisinde bahsedildiği gibi panel alt yüzeyi ile kanal yüzeyi arası mesafenin azalması sonucu akış hızının artmasından kaynaklanmaktadır (Şekil 8b). Kanal girişinde bu mesafenin artması sonucu akışkan hızının düşmesi ile birlikte hücre sıcaklıkları da artmıştır.

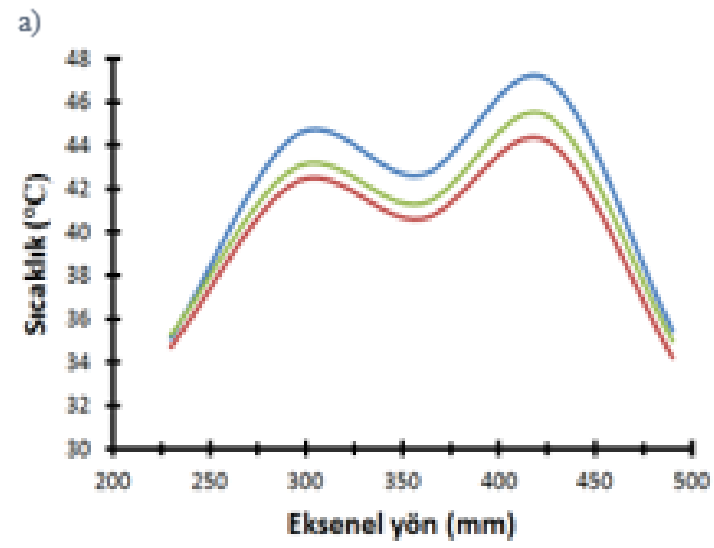

b)

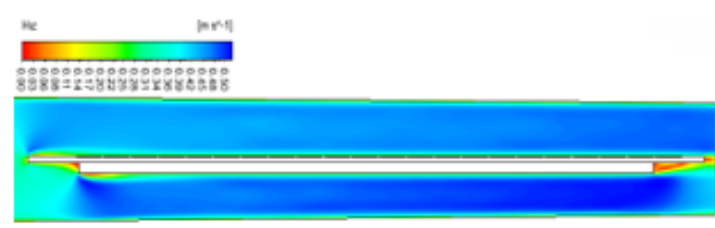

Şekil 8. Eksenel konumun etkisi a) hücre sicaklıkları, b) hız kontörleri $(\mathrm{h} / \mathrm{H}=0,8$, $1 / \mathrm{L}=0,99, \mathrm{k} / \mathrm{H}=0,5$ )

Panelin radyal yönde farklı konumlara yerleştirilmesi Şekil 9'dan da anlaşıldığı gibi panelin üst yüzeye yakın olması durumunda ilk sıralardaki hücre sıcaklıklarının artmasına sebep olmuştur. Panel üzerinde son sıralara yaklaşıldığında ise hücre sıcaklıkları tüm parametre değerleri için yaklaşık olarak aynı kalmıştır. 


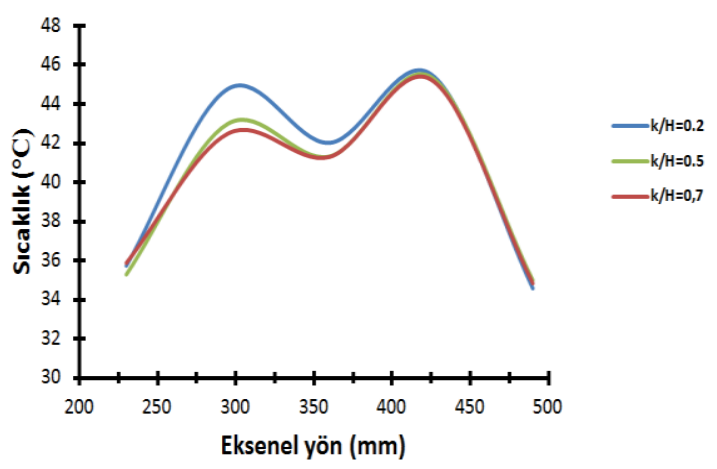

Şekil 9. Radyal konumun etkisi

Şekil 10'da kanal çıkışındaki daralma miktarının ve panel konumunun değişimi sonucunda oluşan basınç kayıpları görülmektedir. En yüksek basınç kaybının kanal çıkışının daralması sonucu $(\mathrm{h} / \mathrm{H}=0,6)$ daralmanın olmadığı duruma göre oluştuğu anlaşılmaktadır. Eksenel yönde kanal çıkışına yakın bölgeye panelin yerleştirilmesi sonucunda ise basınç kaybı bir miktar artmış fakat radyal yöndeki farklı konumlar küçük değişimler göz ardı edildiğinde basınç kaybını etkilememiştir.

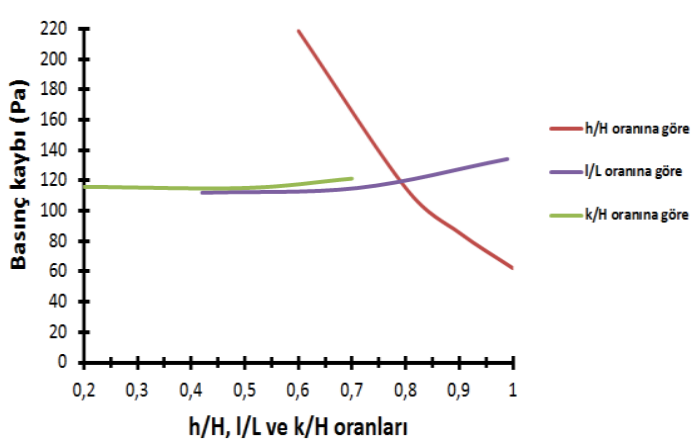

Şekil 10. Farklı parametre değerlerindeki basınç kayıpları

\section{SONUÇLAR}

Sayısal çalışma sonucunda elde edilen bulgular kanal çıkışının daraltılması ve panelin eksenel konumunun kanal çıkışına yakın olması durumunda fotovoltaik hücreler için daha etkin soğutma koşullarının sağlandığını göstermektedir. En yüksek 1s1 transferi $\mathrm{h} / \mathrm{H}$ oranının $\mathrm{h} / \mathrm{H}=0,6$ olduğu durumda elde edilmiştir. Kanal çıkışının daraltılması panelin kanal çıkışına yakın bölgeye yerleştirilmesi durumuna göre fotovoltaik hücre sıcaklıklarının dağılımına daha fazla etki etmektedir. Raydal yöndeki panel konumu ise panelin üst yüzeye yakın olması durumunda ilk sıralardaki hücre sıcaklıklarının artmasına sebep olmuştur. Panel üzerinde son siralara yaklaşıldığında ise hücre sıcaklıkları tüm parametre değerleri için yaklaşık olarak aynı kalmıştır. Diğer yandan $\mathrm{h} / \mathrm{H}$ oranının düşürülmesi 1S1 transferi ile birlikte basınç kaybını da en fazla oranda artırmaktadır. Bu nedenle çalışmada ele alınan parametre değerlerinin sistemin soğutma ihtiyacına göre en uygun şekilde belirlenmesi gerekmektedir.

\section{KAYNAKLAR}

1. Royne, A., Dey, C.J., Mills, D.R., 2005. Cooling of Photovoltaic Cells under Concentrated Illumination: A Critical Review, Sol. Energy Mater. Sol. Cells, vol. 86, no. 4, pp. $451-483$.

2. Liu, L., Zhu, L., Wang, Y., Huang, Q., Sun, Y., Yin, Z., 2011. Heat Dissipation Performance of Silicon Solar Cells by Direct Dielectric Liquid Immersion under Intensified Illuminations, Sol. Energy, vol. 85, no. 5, pp. 922-930.

3. Zhu, L., Boehm, R.F., Wang, Y., Halford, C., Sun, Y., 2011. Water Immersion Cooling of PV Cells in a High Concentration System, Sol. Energy Mater. Sol. Cells, vol. 95, no. 2, pp. 538-545.

4. Sheeba, K.N., Rao, R.M., Jaisankar, S., 2015. A Study on the Underwater Performance of a Solar Photovoltaic Panel, Energy Sources, Part A Recover. Util. Environ. Eff., vol. 37, no. 14, pp. 1505-1512.

5. Florschuetz, L.W., Truman, C.R., Metzger, D.E., 1981. Streamwise Flow and Heat Transfer Distributions for Jet Array Impingement with Crossflow, J. Heat Transfer, vol. 103, no. 2, p. 337.

6. Min, C., Nuofu, C., Xiaoli, Y., Yu, W., Yiming, B., Xingwang, Z., 2009. Thermal Analysis and Test for Single Concentrator Solar Cells, J. Semicond., Chinese Institute of Electronics, vol. 30, no. 4.

7. Natarajan, S.K., Mallick, T.K., Katz, M., Weingaertner, S., 2011. Numerical 
Investigations of Solar Cell Temperature for Photovoltaic Concentrator System with and Without Passive Cooling Arrangements, Int. J. Therm. Sci., vol. 50, no. 12, pp. 2514-2521.

8. Coventry, J.S., 2005. Performance of a Concentrating Photovoltaic/thermal Solar Collector, Sol. Energy, vol. 78, no. 2, pp. 211-222.

9. Sun, Y., Wang, Y., Zhu, L., Huang, Q., Xiang, H., 2016. Simulation Study of a Linear Concentrating Photovoltaic Receiver with Direct Liquid-Immersed Solar Cells, Sol. Energy, vol. 124, pp. 1-14.

10. Xiang, H., Wang, Y., Zhu, L., Han, X., Sun, Y., Zhao, Z., 2012. 3D Numerical Simulation on Heat Transfer Performance of a Cylindrical Liquid Immersion Solar Receiver, Energy Convers. Manag., vol. 64, pp. 97-105. 